\title{
Occupational groups and its physical and mental health correlates: results from the Singapore Mental Health Study 2016
}

\author{
Rajeswari Sambasivam $^{1}{ }^{10} \cdot$ Anitha Jeyagurunathan $^{1} \cdot$ Edimansyah Abdin $^{1} \cdot$ Saleha Shafie $^{1} \cdot$ Sherilyn Chang $^{1}$. \\ Janhavi Ajit Vaingankar ${ }^{1}$. Siow Ann Chong ${ }^{1} \cdot$ Mythily Subramaniam ${ }^{1}$
}

Received: 10 May 2021 / Accepted: 23 June 2021 / Published online: 24 July 2021

(c) The Author(s) 2021

\begin{abstract}
Purpose The physical and mental wellbeing of an individual is impacted by the type occupation one does. This study aims to establish the prevalence of mental and physical disorders, the association of occupational groups and health-related quality of life, and the extent of work-loss and work-cut back in past 30 days among the employed in the Singapore resident population. Methods Data from a population-based, epidemiological survey of a representative sample of Singapore citizens and permanent residents aged 18 years and above were used. Lifetime diagnosis of select mental disorders was established using the World Health Organization's Composite International Diagnostic Interview version 3.0 (WHO-CIDI 3.0). Data on nicotine dependence, work productivity, quality of life and socio-demographics were obtained via self-report. Ten major occupational groups based on the Singapore Standard Occupational Classification were included in the analysis.

Results The sample comprised 4021 employed individuals who were predominantly males (54.7\%) and aged 35-49 years (35.4\%). 'Service and sales workers' (22.6\%), 'Professionals' (17.3\%) and 'Legislators, senior officials and managers' $(16.4 \%)$ were the three largest occupational groups. Socio-demographic characteristics differed significantly $(p<0.001)$ across all occupational groups. Lifetime prevalence of mood disorders among the employed was $8.4 \%$ and the most prevalent physical disorder was chronic pain (18.9\%). No significant differences were observed in work productivity loss across the occupational groups.

Conclusions The disparities in the socio-demographic characteristics and prevalence of mental and physical disorders across occupational categories provide policymakers with vital information to pilot effective interventions that can improve the psychosocial and physical conditions at work.
\end{abstract}

Keywords Occupational groups $\cdot$ Physical conditions $\cdot$ Mental wellbeing $\cdot$ Psychosocial

\section{Introduction}

Majority of people's time is spent working and thus the workplace "is one of the key environments that affect their mental wellbeing and health" (World Health Organization 2000). The effect of having an occupation may be a doubleedged sword; creating a positive impact on one's wellbeing

Rajeswari Sambasivam and Anitha Jeyagurunathan have contributed equally to this work.

Rajeswari Sambasivam

Rajeswari_sambasivam@imh.com.sg

1 Research Division, Institute of Mental Health, Singapore, Buangkok Green Medical Park, 10 Buangkok View, Singapore 539747, Singapore by providing a sense of personal identity and financial security whilst on the other hand it may cultivate pressure due to the increasing demands of modern-day work life, which, in turn affects the physical and mental wellbeing of an individual (International Labour Organization 2016).

Studies conducted across European and North American countries have shown that different types of occupations are associated with high rates of mental disorders; people involved in occupations such as sales, services, clerical, teaching, welfare workers, cooking seem to be particularly at risk (Stansfeld et al. 2011). Studies of psychosocial work characteristics and mental health revealed that job strain leads to increased risk of depression and other common mental disorders (Stansfeld and Candy 2006; Netterstrom et al. 2008). It has also been widely established that physical conditions such as asthma and other respiratory symptoms 
(Dodd and Mazurek 2016; Schyllert et al. 2018) differ in prevalence among occupational groups. Studies have shown that workplace productivity loss is associated with physical and mental health conditions (Boles et al. 2004; Mitchell and Bates 2011). Holden (2011) recognized that psychological distress when present as a co-morbid condition determines an increased risk of productivity loss for a variety of health conditions.

Singapore is a country in Southeast Asia with a total population of about 6 million. Chinese (74.4\%) form the majority of the population, followed by Malays (13.4\%), Indians $(9.0 \%)$ and those from other ethnic groups (3.2\%) (SingStat 2019). In 2019, 80.8\% of Singapore resident population aged 25-64 years was employed. Of these, 58.3\% were in professionals, managerial, executive and technical (PMET) occupational group, 22.2\% were in clerical, sales and service workers group and $19.5 \%$ made up the production and transport operators, cleaner and labourers occupational group (Ministry of Manpower 2019). Using data from the Singapore Mental Health Study, a populationwide epidemiological study conducted in Singapore in 2010, Vaingankar et al. (2015) reported that the lifetime prevalence of having 'any physical disorder' and 'any mental disorder' among those employed, were $37.9 \%$ and $13.0 \%$ respectively, with hypertension being the most prevalent physical disorder (15.6\%) and major depressive disorder being the most prevalent mental disorder (5.9\%).

Following the completion of the second Singapore Mental Health Study conducted in 2016 (henceforth referred to as SMHS 2016) (Subramaniam et al. 2019), this present study set out to establish (1) the prevalence of mental and physical disorders among the employed in Singapore, (2) the association of occupational groups and health-related quality of life, and (3) the extent of work-loss and work-cut back in past 30 days in the Singapore resident population.

\section{Methods}

\section{Survey population and procedure}

Data for this study were gathered from the SMHS 2016; a population-based, epidemiological study conducted between 2016 and 2018. The study was approved by the National Healthcare Group Domain Specific Review Board (NHG DSRB). Survey respondents were randomly selected $(N=15,900)$ from a national database of Singapore citizens and permanent residents aged 18 years and above $(N=311,687)$. Residents who were institutionalised or hospitalised for the duration of the study, unable to do the interview due to severe physical or mental illness, those living outside of Singapore, and those who were unable to communicate either in English, Mandarin or Malay were excluded from the study. A disproportionate stratified sampling design was used to over-sample residents aged 65 and above, and those of Malay and Indian ethnicity to ensure that sufficient samples sizes were achieved to improve the reliability of estimates for these groups. An invitation letter was sent to each resident which was followed by an interviewer visiting their homes to obtain their written informed consent to participate in the study. Trained interviewers from a survey research firm conducted the face-to-face interviews with residents who agreed to participate in the study. Further methodological details can be found in an earlier paper (Subramaniam et al. 2019).

The overall survey response rate was $69.5 \%$ and a total of 6126 respondents participated in the study. Respondents were queried about their employment situation during the time of the survey by asking them to indicate if they were "working now for pay, self-employed, looking for work, disabled, temporarily laid off, retired, a home-maker, a full-time or part-time student or, have never worked". Respondents then had to also specify their occupation and the industry they worked in. The employment level in Singapore ranged from $67.7 \%$ to $68.3 \%$ between 2015 and 2019 (Ministry of Manpower Singapore 2020). Data from 4021 employed respondents were categorized into the following employment groups according to ten major occupational groups based on the Singapore Standard Occupational Classification (SSOC 2020): 1. Business owners, 2. Legislators, senior officials and managers, 3. Professionals, 4. Associate professionals and technicians, 5. Clerical support workers, 6 . Service and sales workers, 7. Craftsmen and related trades workers, 8. Plant and machine operators and assemblers, 9. Cleaners, labourers and related workers and 10. Agricultural and fishery workers. The classification of the occupational groups followed that of earlier research in this area (Vaingankar et al. 2015). The occupational group 'Agricultural and fishery workers' $(n=3)$ was excluded from the analysis due to low sample size.

\section{Mental disorders}

The fully structured computer-assisted personal interview version of the Composite International Diagnostic Interview version 3.0 (WHO-CIDI 3.0) (Kessler and Ustün 
2004) is designed to generate diagnostic information according to definitions and criteria of the Diagnostic and Statistical Manual of Mental Disorders, 4th Edition (DSMIV) (APA 1994) and the International Classification of Disease, 10th Revision (ICD-10), Classification of Mental and Behavioral Disorders (WHO 1992). Select diagnostic modules of the WHO-CIDI 3.0, major depressive disorder (MDD), bipolar disorder (BD), generalized anxiety disorder (GAD), obsessive compulsive disorder (OCD), and alcohol use disorder (AUD) which includes alcohol abuse and alcohol dependence, were administered to the respondents to reduce respondent burden. For this study MDD and BD were classified as mood disorders and GAD and OCD as anxiety disorders.

\section{Chronic physical conditions}

Interviewers read out a list of 18 chronic physical conditions and asked participants to report if the latter were 'ever told by a Doctor' that they had any of these conditions. These chronic conditions included hypertension, hyperlipidaemia, diabetes, asthma, chronic pain (arthritis or rheumatism, back problems such disk or spine problems, and migraine headaches), cardiovascular disorders (stroke or major paralysis, and heart disease including heart attack, coronary heart disease, angina and congestive heart failure), ulcers and chronic inflamed bowel problems such as enteritis or colitis, thyroid diseases, cancer, kidney failure, neurological disorders (epilepsy, convulsions and Parkinson's disease) and chronic lung diseases (chronic bronchitis or emphysema). In this article, we have excluded cardiovascular disorders, ulcers and chronic inflamed bowel problems, thyroid diseases, cancer, kidney failure, neurological disorders and chronic lung diseases due to their low prevalence i.e., less than 5.0\% (Schäfer 2012) in the population. Hypertension, hyperlipidaemia, diabetes, asthma and chronic pain (arthritis or rheumatism, back problems such disk or spine problems, and migraine headaches) have been included for the purpose of this study.

\section{Nicotine dependence}

The 6-item modified Fagerstrom Test for Nicotine Dependence was used to assess the intensity of physical dependence on nicotine. Scores of 4 and less are categorised as low dependence and scores of $8-10$, as high dependence.
As defined by a previous study (Shahwan et al. 2019), we classified those with scores 5 and above as dependence.

\section{Work productivity}

The effect of mental and physical disorders on work productivity was assessed using the 30-day functioning module of the WHO-CIDI 3.0. The number of days when respondents were totally unable to work or carry out their regular activities, or had to cut back on the quality and quantity of their work due to problems with their physical health, mental health, or use of alcohol or drugs in the month preceding the survey were reported as work-loss and work-cut-back days respectively.

\section{Health-related quality of life}

The Short Form 12-item (SF-12) Health Survey Questionnaire is an abbreviated version of the SF-36, and is commonly included in population-based studies to assess perceived health status (Ware et al. 1996), and in clinical and community settings (SF-12, 2002). Thus, the SF-12 measures eight concepts commonly represented in widely used surveys: physical functioning (PF), role limitations due to physical health problems (RP), bodily pain (BP), general health $(\mathrm{GH})$, vitality (energy/fatigue) (VT), social functioning (SF), role limitations due to emotional problems (RE), and mental health (psychological distress and psychological wellbeing) (MH). The developers have suggested obtaining summary scores from the instrument, the intention being to reduce the original eight-scale profile to two summary measures without substantial loss of information. The summary measures were constructed independently to reproduce corresponding SF-12 physical and mental health summary measures. Scores ranged from 1 (the worst possible health) to 100 (the best possible health). The physical component summary scores (PCS) and mental component score (MCS) have evidence of reliability, validity and responsiveness in population studies (Ware et al. 1996).

\section{Socio-demographic information}

Respondents' socio-demographic information on age, gender, ethnicity, marital status, highest education level, average household income and employment status were obtained via a structured questionnaire. 


\section{Statistical analysis}

All estimates were weighted to adjust for over sampling, non-response and post-stratified for age and ethnicity distributions between the survey sample and the Singapore resident population in 2014 to ensure that the survey findings were representative of the Singapore adult population. Descriptive analyses were performed to describe the socio-demographic profile of the study population and lifetime prevalence of physical and mental disorders across occupational groups. Associations between occupational groups and other categorical variables were examined using $\chi^{2}$ test and multivariable logistic regression analyses. The multicollinearity between independent variables was analyzed using a variance inflation factor (VIF) command, with a VIF value of more than 10 considered as indicative of multicollinearity. We found that the VIF values ranged from 1.07 to 3.03. Statistical significance was set at $p<0.05$ and all statistical analyses were performed using the Statistical Analysis Software (SAS) system version 9.3 (Cary, NC, USA). Missing values in this dataset were handled using the listwise method.

\section{Results}

\section{Occupation and socio-demographic characteristics}

Four thousand and twenty-one employed individuals were included in this study sample. Majority of the participants were males (54.7\%), aged 35-49 years (35.4\%), of Chinese ethnicity (75.9\%), married (62.5\%), attained university education level $(35.1 \%)$, with a household income of \$6000-9999 (24.1\%) (Table 1). The top three occupational groups were 1 . Service and sales workers (22.6\%), 2. Professionals (17.3\%) and 3. Legislators, senior officials and managers (16.4\%). Age group, gender, ethnicity, marital status, educational level and household income showed significant $(p<0.001)$ differences across all occupational groups (Table 2). The most common occupational group among the older aged participants (50 years and above) was 'Cleaners, Labourers and Related Workers' whilst 'Legislators, senior officials and managers' and 'Professionals' were the most common occupations among those aged 35-49 and 18-34 years, respectively.
Table 1 Socio-demographic characteristics of the respondents

\begin{tabular}{|c|c|c|}
\hline & $N(4021)$ & $\%$ \\
\hline \multicolumn{3}{|l|}{ Age group } \\
\hline $18-34$ & 1219 & 30.9 \\
\hline $35-49$ & 1246 & 35.4 \\
\hline $50-64$ & 1178 & 28.0 \\
\hline $65+$ & 378 & 5.8 \\
\hline \multicolumn{3}{|l|}{ Gender } \\
\hline Male & 2303 & 54.7 \\
\hline Female & 1718 & 45.3 \\
\hline \multicolumn{3}{|l|}{ Ethnicity } \\
\hline Chinese & 1212 & 75.9 \\
\hline Malay & 1249 & 12.2 \\
\hline Indian & 1228 & 8.7 \\
\hline Others & 332 & 3.3 \\
\hline \multicolumn{3}{|l|}{ Marital status } \\
\hline Never married & 1041 & 30.2 \\
\hline Married & 2630 & 62.5 \\
\hline Divorced/separated & 250 & 5.6 \\
\hline Widowed & 100 & 1.8 \\
\hline \multicolumn{3}{|l|}{ Education } \\
\hline Primary and below & 508 & 11.9 \\
\hline Secondary & 966 & 19.9 \\
\hline Pre-U/Junior College & 166 & 4.8 \\
\hline Vocational Institute/ITE & 405 & 7.3 \\
\hline Diploma & 805 & 21.0 \\
\hline University & 1171 & 35.1 \\
\hline \multicolumn{3}{|l|}{ Household Income (SGD) } \\
\hline Below 2000 & 514 & 10.4 \\
\hline 2000-3999 & 930 & 19.7 \\
\hline $4000-5999$ & 845 & 22.7 \\
\hline $6000-9999$ & 782 & 24.1 \\
\hline 10,000 and above & 698 & 23.1 \\
\hline
\end{tabular}

SGD Singapore Dollar

\section{Prevalence of mental and physical disorders across occupational groups}

The lifetime prevalence of mental disorders among participants across occupational groups is shown in Table 3 . The prevalence of nicotine dependence was significantly different $(p<0.001)$ across the occupational groups. Mood and anxiety disorders were observed to be the most prevalent mental disorders among 'Clerical support workers' while alcohol use disorder and nicotine dependence were more prevalent among 'Business owners' and 'Plant and machine operators 


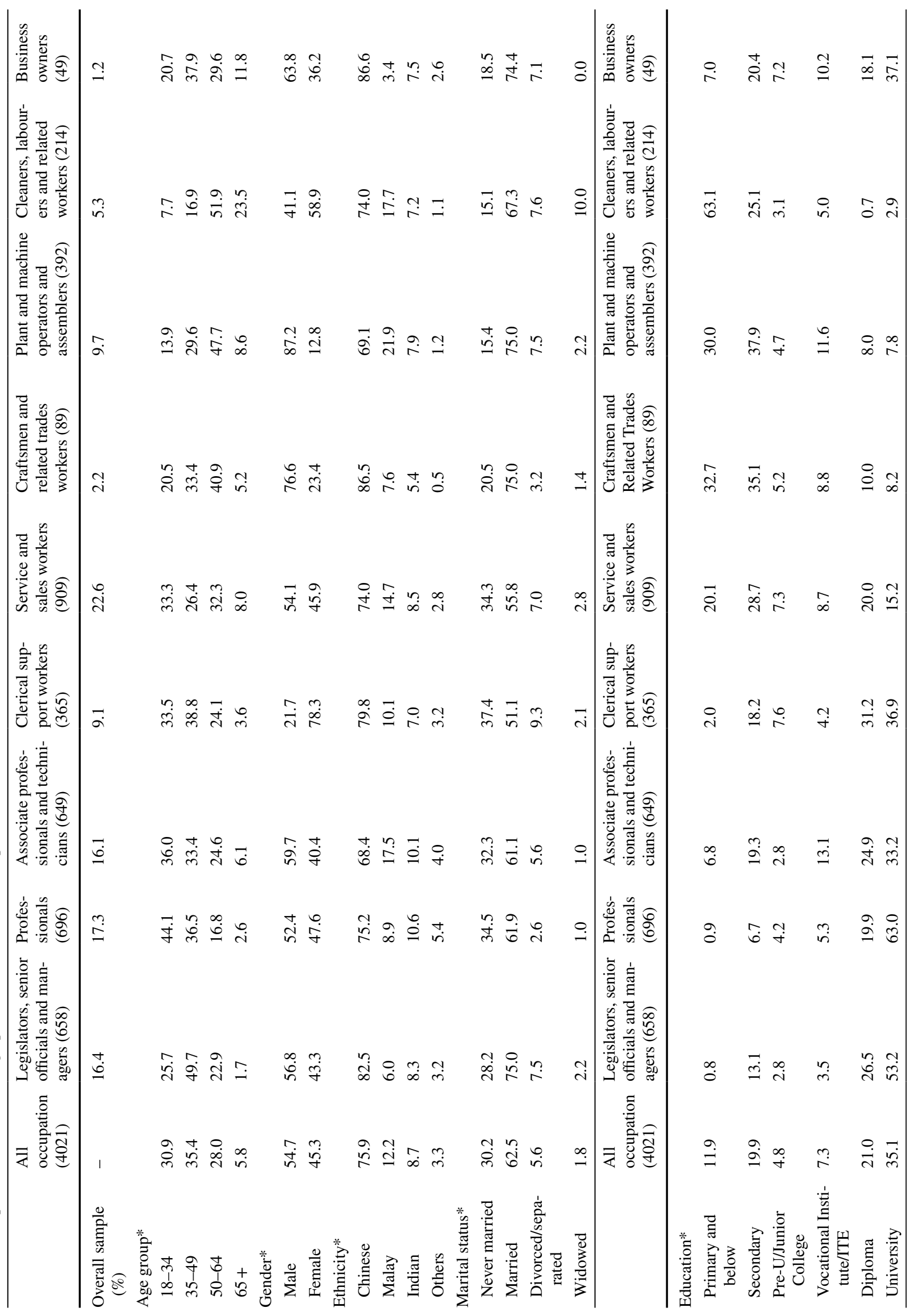




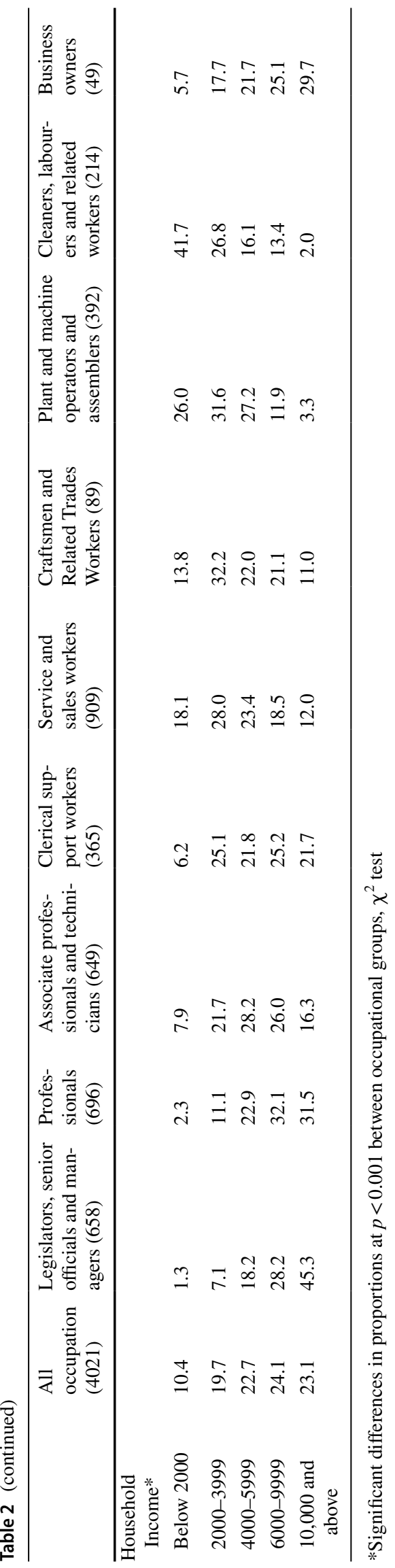

and assemblers', respectively. However, after controlling for socio-demographic variables, 'Clerical support workers' were more likely to have anxiety disorder compared to 'Associate professionals and technicians' ( $\mathrm{OR}=2.31, \mathrm{CI}$ $1.02,5.23, p=0.04$ ) (refer to Table 4).

Table 5 describes the lifetime prevalence of chronic conditions among the different occupational groups. Hypertension $(p<0.001)$, diabetes $(p<0.001)$ and chronic pain $(p=0.02)$ have significant differences across the occupational groups. Hypertension and hyperlipidemia were notably more prevalent among 'Cleaners, labourers and related workers'. The highest prevalence of diabetes and chronic pain was seen among 'Plant and machine operators and assemblers', and 'Business owners' respectively. After controlling for socio-demographic variables, 'Legislators, senior officials and managers' $(\mathrm{OR}=2.06, \mathrm{CI} 1.06,4.01, p=0.03)$ were more likely to have diabetes compared to 'Associate professionals and technicians' (refer to Table 6).

\section{Health-related quality of life and work productivity}

Table 7 shows the mean scores of the health-related quality of life domains (physical component score and mental component score) across occupational groups. Higher means were observed in the mental component scores when compared to the physical component scores across the occupational groups. We conducted a linear regression and observed that 'Craftsmen and related trades workers' $(\beta=1.79,95 \%$ CI $0.52 ; 3.07, p<0.01)$ were significantly associated with higher health-related quality of life in mental component score (MCS) compared to 'Associate professionals and technicians'.

The differences by occupation in the work-loss days and work-cutback days did not reach statistical significance (Table 8), nevertheless, variations were seen across the occupational groups. The highest work-loss (mean 1.11) and work-cutback (mean 0.75) days due to health was reported among 'Business owners' and 'Professionals' respectively.

\section{Discussion}

One of the main objectives of this paper was to examine the associations between occupational groups and sociodemographic characteristics. The differences in age, gender, ethnicity, marital status, educational level and household income across occupational groups are consistent with reports from studies conducted in other populations (Lim et al. 2000; Kessler et al. 2006; De Graaf et al. 2012). 
Table 3 Prevalence of lifetime mental disorders across occupational categories

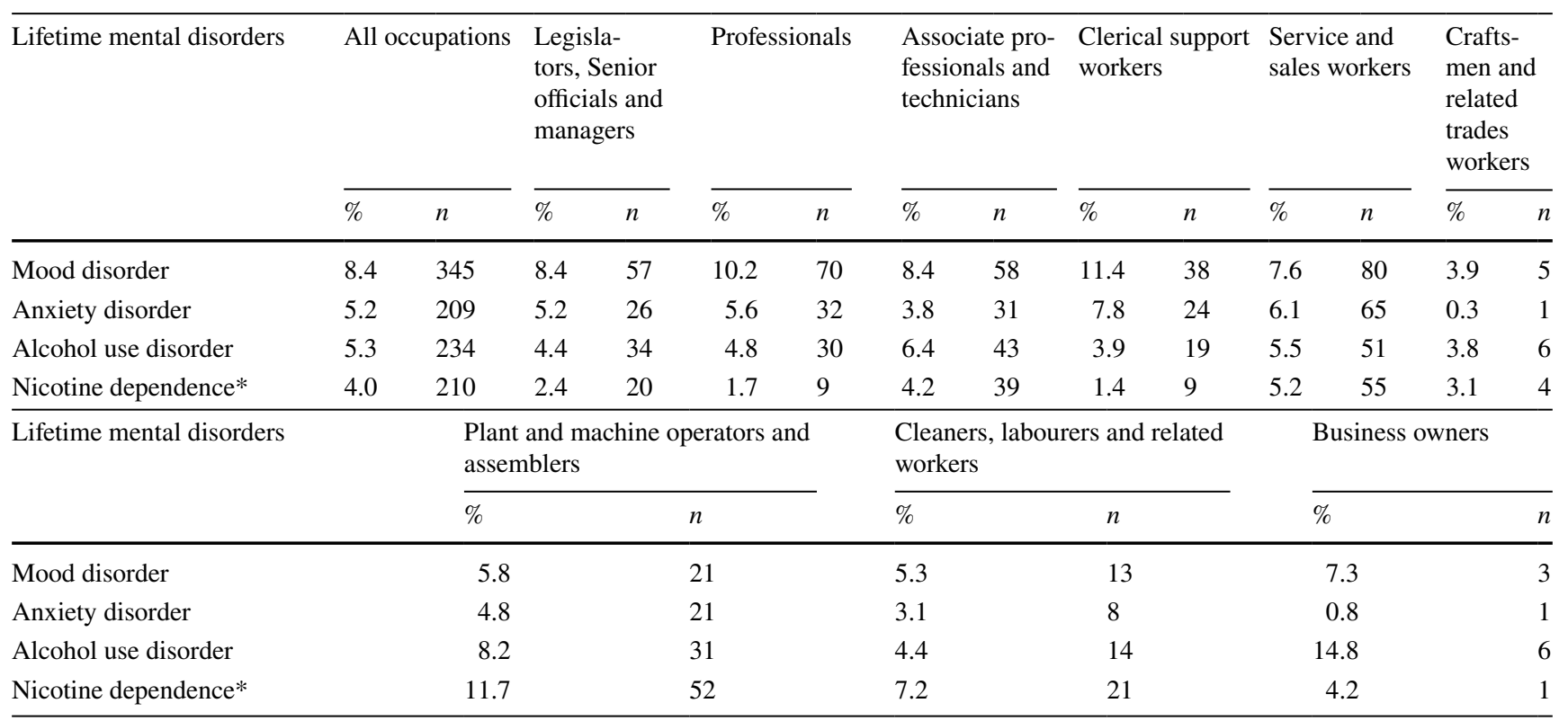

*Significant differences at $p<0.001$ between occupational groups, $\chi^{2}$ test

\section{Prevalence of mental disorders across occupational groups}

The overall lifetime prevalence of mood disorders among the employed was $8.4 \%$ and it was the most frequently endorsed category of disorders in this sample. Sanderson and Andrews (2006) conducted a structured review of epidemiological studies in workplaces and similarly found depression to be the most prevalent disorder among the employed. Mood and anxiety disorders tend to be more commonly reported (Kawakami et al. 1996; Andrea et al. 2004; Linden and Muschalla 2007; Cohidon et al. 2009) in workplace-related surveys and notably office job workers report elevated levels of anxiety and depression (Kang et al. 2016). A similar observation was made in the current study sample, whereby office job workers (i.e., "Legislators, senior officials and managers", "Professionals", "Associate professionals and technicians" and "Clerical support workers") reported higher rates of mood and anxiety disorders. This could be attributed to long working hours and the job scope as office workers tend to have highly demanding jobs with limited support and resources which become potential risk factors for mental health problems (Karasek 1979; Kang et al. 2016). Andrea et al. (2004) found that subclinical anxiety was associated with jobs with increased psychological demands and conflicts with supervisors while subclinical depression was associated with low decision latitude and decreased social support. Tak (2002) reported a similar finding stating that workplace conflict such as, conflict between departments, and decision-making were the most critical factors contributing to job stress among office workers. Our study further substantiates these findings as 'Craftsmen and related trades workers' (i.e., manual workers) reported significantly higher MCS score compared to 'Associate professionals and technicians' (office job workers).

Nicotine dependence was observed to be the highest among 'Plant and machine operators and assemblers' which coincides with the findings of Siahpush et al., (2006) in a panel study comprising 2000 adult smokers from each of four countries: the United States, Canada, United Kingdom, and Australia. Higher rates of nicotine dependence were largely found among blue-collar professions and those with lower levels of education (Lee et al. 2004; Pennanen et al. 2014). Alcohol use disorder, on the other hand, has been associated with "upper managers" 
(Marchand 2008; Parker 1992) which has been similarly noted in our study sample among 'Business owners'. Zhang and Snizek (2003) discussed how job independence and satisfaction have negligible effect on alcohol use and on the contrary, steady employment has the most distinct harmful effect on alcohol use. Different work positions may contribute to the various rates of alcohol use; upper managers tend to view it as a way to unwind after a day's work or engage in alcohol consumption for work-related networks (Järvinen et al. 2014). Upper managers tend to have a higher income level and this is associated with increased drinking patterns which may be partly explained by the fairly high prices of alcoholic beverages in Singapore (Lim et al. 2007).

\section{Prevalence of physical disorders across occupational groups}

Whilst mental disorders were predominantly associated with skilled office workers, hypertension and diabetes was found to have the highest prevalence among those who engage in heavy manual work; 'Cleaners, labourers and related workers' and 'Plant and machine operators and assemblers', respectively (Nakamura 2000; Smith 1997). Previous studies that have mainly looked at metabolic syndrome between manual and non-manual workers have consistently reported that manual workers tend to be at a higher risk of the condition due to lower education and poorer socioeconomic status that is linked to poor health practices such as unhealthy dietary habits, lack of exercise, unhealthy behaviours such as smoking and poor health literacy (Sanchez-Chaparro et al. 2008; Gupta et al. 2012). On the contrary, chronic pain was highly prevalent among business owners which has been similarly observed among Japanese white-collar workers with Wakaizumi et al. (2017) reporting an increasing trend in the prevalence of chronic pain. Although pain has been traditionally associated with manual workers (Bernard et al. 2011) recent studies have posited that stressors (commonly found among white-collared workers) such as low job control with high job demands and job stress that is not adequately reciprocated with rewards (i.e. promotion, salary raise, praise) are predictors of chronic pain (Herr et al. 2015).

\section{Work productivity}

With all these in play, the effect of the mental and physical conditions on work-loss days was notably the highest among 'Business owners' and lowest among 'Professionals'. As for work-cutback days, we found that it was highest among 'Professionals' and lowest among 'Business owners'. The plausible reason for these observations could be that that those in the 'Professionals' category might be more able than others 
Table 5 Prevalence of lifetime chronic conditions across occupational categories

\begin{tabular}{|c|c|c|c|c|c|c|c|c|c|c|c|c|c|c|}
\hline \multirow[t]{2}{*}{ Lifetime chronic conditions } & \multicolumn{2}{|c|}{$\begin{array}{l}\text { All occupa- } \\
\text { tions }\end{array}$} & \multicolumn{2}{|c|}{$\begin{array}{l}\text { Legislators, } \\
\text { senior officials } \\
\text { and managers }\end{array}$} & \multicolumn{2}{|c|}{ Professionals } & \multicolumn{2}{|c|}{$\begin{array}{l}\text { Associate pro- } \\
\text { fessionals and } \\
\text { technicians }\end{array}$} & \multicolumn{2}{|c|}{$\begin{array}{l}\text { Clerical sup- } \\
\text { port workers }\end{array}$} & \multicolumn{2}{|c|}{$\begin{array}{l}\text { Service and } \\
\text { sales workers }\end{array}$} & \multicolumn{2}{|c|}{$\begin{array}{l}\text { Craftsmen } \\
\text { and related } \\
\text { trades } \\
\text { workers }\end{array}$} \\
\hline & $\%$ & $n$ & $\%$ & $n$ & $\%$ & $n$ & $\%$ & $n$ & $\%$ & $n$ & $\%$ & $n$ & $\%$ & $n$ \\
\hline Hypertension** & 18.7 & 800 & 19.2 & 120 & 15.4 & 110 & 17.0 & 131 & 12.2 & 51 & 18.7 & 190 & 18.4 & 19 \\
\hline Hyperlipidaema & 19.4 & 799 & 16.1 & 115 & 17.4 & 113 & 18.3 & 124 & 21.2 & 65 & 19.9 & 188 & 24.6 & 23 \\
\hline Diabetes** & 7.2 & 438 & 6.9 & 53 & 3.5 & 45 & 4.9 & 58 & 4.5 & 33 & 7.4 & 115 & 12.6 & 14 \\
\hline Asthma & 11.9 & 514 & 8.4 & 63 & 14.5 & 101 & 13.1 & 88 & 15.3 & 56 & 13.1 & 127 & 11.1 & 9 \\
\hline Chronic pain* & 18.9 & 770 & 22.9 & 147 & 19.2 & 153 & 18.4 & 115 & 20.8 & 81 & 16.7 & 147 & 3.4 & 8 \\
\hline \multirow[t]{2}{*}{ Lifetime chronic conditions } & & \multicolumn{5}{|c|}{$\begin{array}{l}\text { Plant and machine operators and } \\
\text { assemblers }\end{array}$} & \multicolumn{4}{|c|}{$\begin{array}{l}\text { Cleaners, labourers and related } \\
\text { workers }\end{array}$} & \multicolumn{4}{|c|}{ Business owners } \\
\hline & & \multicolumn{2}{|c|}{$\%$} & \multicolumn{3}{|c|}{$n$} & \multicolumn{2}{|l|}{$\%$} & \multicolumn{2}{|l|}{$n$} & \multicolumn{2}{|c|}{$\%$} & & $n$ \\
\hline Hypertension** & \multicolumn{3}{|c|}{29.8} & \multicolumn{3}{|c|}{104} & \multicolumn{2}{|l|}{31.5} & \multicolumn{2}{|c|}{66} & \multicolumn{3}{|c|}{17.8} & 9 \\
\hline Hyperlipidaema & \multicolumn{3}{|c|}{25.3} & \multicolumn{3}{|c|}{100} & 25.4 & & \multicolumn{2}{|c|}{60} & \multicolumn{3}{|c|}{22.4} & 11 \\
\hline Diabetes** & \multicolumn{3}{|c|}{16.0} & \multicolumn{3}{|c|}{70} & 14.9 & & \multicolumn{2}{|c|}{43} & \multicolumn{3}{|c|}{13.2} & 7 \\
\hline Asthma & \multicolumn{3}{|c|}{7.6} & \multicolumn{3}{|c|}{36} & 9.4 & & \multicolumn{2}{|c|}{29} & \multicolumn{3}{|c|}{12.2} & 5 \\
\hline Chronic pain* & \multicolumn{3}{|c|}{16.1} & & 3 & & 18.3 & & 41 & & & 28.9 & & 15 \\
\hline
\end{tabular}

*Significant differences at $p<0.05$

${ }^{* *}$ Significant differences at $p<0.001$ between occupational groups, chi-square test

Table 6 Odds of having lifetime chronic conditions across occupational categories

\begin{tabular}{|c|c|c|c|c|c|c|c|c|c|c|c|c|}
\hline \multirow[t]{2}{*}{ Occupational categories } & \multicolumn{4}{|c|}{ Hypertension } & \multicolumn{4}{|c|}{ Hyperlipidemia } & \multicolumn{4}{|c|}{ Diabetes } \\
\hline & \multirow{2}{*}{$\begin{array}{c}\text { OR } \\
\text { Ref }\end{array}$} & \multicolumn{2}{|c|}{$\begin{array}{l}95 \% \\
\text { Confidence } \\
\text { Interval }\end{array}$} & \multirow[t]{2}{*}{$p$ value } & \multirow{2}{*}{$\begin{array}{c}\text { OR } \\
\text { Ref }\end{array}$} & \multicolumn{2}{|c|}{$\begin{array}{l}95 \% \\
\text { Confidence } \\
\text { Interval }\end{array}$} & \multirow[t]{2}{*}{$p$ value } & \multirow{2}{*}{$\begin{array}{c}\text { OR } \\
\text { Ref }\end{array}$} & \multicolumn{2}{|c|}{$\begin{array}{l}95 \% \text { Confi- } \\
\text { dence Interval }\end{array}$} & \multirow[t]{2}{*}{$p$ value } \\
\hline Associate professionals and technicians & & & & & & & & & & & & \\
\hline Legislators, senior officials and managers & 1.27 & 0.79 & 2.05 & 0.330 & 0.73 & 0.46 & 1.17 & 0.193 & 2.06 & 1.06 & 4.01 & 0.033* \\
\hline Professionals & 1.27 & 0.77 & 2.10 & 0.346 & 1.22 & 0.76 & 1.97 & 0.403 & 1.05 & 0.50 & 2.22 & 0.897 \\
\hline Clerical support workers & 0.76 & 0.42 & 1.39 & 0.380 & 1.62 & 0.97 & 2.72 & 0.067 & 1.17 & 0.55 & 2.49 & 0.683 \\
\hline Service and sales workers & 0.98 & 0.62 & 1.54 & 0.915 & 1.03 & 0.67 & 1.56 & 0.901 & 1.15 & 0.62 & 2.14 & 0.660 \\
\hline Craftsmen and related trades workers & 0.67 & 0.27 & 1.65 & 0.382 & 1.08 & 0.48 & 2.41 & 0.849 & 1.82 & 0.63 & 5.23 & 0.267 \\
\hline Plant and machine operators and assemblers & 1.12 & 0.68 & 1.84 & 0.659 & 0.94 & 0.56 & 1.58 & 0.818 & 1.52 & 0.78 & 2.97 & 0.221 \\
\hline Cleaners, labourers and related workers & 1.20 & 0.61 & 2.37 & 0.593 & 0.71 & 0.36 & 1.40 & 0.321 & 1.09 & 0.47 & 2.52 & 0.846 \\
\hline Business owners & 0.88 & 0.27 & 2.89 & 0.829 & 0.95 & 0.33 & 2.78 & 0.931 & 3.40 & 1.03 & 11.26 & $0.045^{*}$ \\
\hline
\end{tabular}

OR was derived using logistic regression analyses after controlling for age, gender, ethnicity, marital status, education and income

OR odds ratio, ${ }^{*} p<0.05$

to slacken at work in response to their health problems and refrain from being absent at work more often. This could be because those in the 'Professionals' category could be more adept at withholding their work-cutback days from their supervisors or the nature of their work might make it easier for them to do so and also possibly they are less prone to have supervisors compared to other workers. Business owners on the other hand might have subordinates to handle majority of the workload and might feel more at ease to be away from work for a longer duration due to health problems.

The cross-sectional design of this study brings forth a key limitation of the study; the incapability to assess causality. In addition, we were unable to determine the temporal association of the work-loss and work-cutback days and occupation with health conditions as we assessed them at different time-points. Occupation was assessed at the point of study entry, and lifetime prevalence was analysed for the health 
Table 7 Health-related quality of life across occupational categories

\begin{tabular}{|c|c|c|c|c|c|c|c|c|c|c|}
\hline \multirow[t]{2}{*}{ Occupational category } & \multirow[t]{2}{*}{ Mean \pm SE } & \multicolumn{4}{|c|}{ Physical component score (PCS) } & \multirow[b]{2}{*}{ Mean \pm SE } & \multicolumn{4}{|c|}{ Mental component score (MCS) } \\
\hline & & $\beta$ & $\begin{array}{l}95 \% \\
\text { dence }\end{array}$ & - & $p$ value & & $\beta$ & $\begin{array}{l}95 \% \\
\text { denc }\end{array}$ & $\begin{array}{l}\text { i- } \\
\text { erval }\end{array}$ & value \\
\hline Associate professionals and technicians & $54.63 \pm 0.25$ & Ref & & & & $55.02 \pm 0.33$ & Ref & & & \\
\hline Legislators, senior officials and managers & $54.56 \pm 0.24$ & -0.12 & -0.74 & 0.50 & 0.709 & $56.06 \pm 0.28$ & 0.73 & -0.20 & 1.67 & 0.125 \\
\hline Professionals & $54.91 \pm 0.24$ & -0.22 & -0.86 & 0.43 & 0.513 & $55.41 \pm 0.30$ & 0.07 & -0.61 & 1.26 & 0.495 \\
\hline Clerical support workers & $54.03 \pm 0.38$ & -0.17 & -0.89 & 0.54 & 0.635 & $55.36 \pm 0.41$ & 0.50 & -0.62 & 1.62 & 0.380 \\
\hline Service and sales workers & $53.45 \pm 0.25$ & 0.01 & -0.61 & 0.63 & 0.965 & $55.54 \pm 0.28$ & 0.23 & -0.73 & 1.19 & 0.640 \\
\hline Craftsmen and related trades workers & $54.70 \pm 0.50$ & -0.58 & -1.67 & 0.50 & 0.293 & $57.03 \pm 0.47$ & 1.79 & 0.52 & 3.07 & $0.006 *$ \\
\hline Plant and machine operators and assemblers & $53.48 \pm 0.39$ & 0.46 & -0.35 & 1.26 & 0.268 & $55.84 \pm 0.39$ & 0.02 & -1.18 & 1.21 & 0.976 \\
\hline Cleaners, labourers and related workers & $52.84 \pm 0.51$ & -0.43 & -1.38 & 0.52 & 0.378 & $56.43 \pm 0.60$ & 0.91 & -0.73 & 2.54 & 0.277 \\
\hline Business owners & $53.88 \pm 0.67$ & 1.16 & -0.93 & 3.25 & 0.277 & $54.61 \pm 1.14$ & -1.22 & -3.84 & 1.54 & 0.401 \\
\hline
\end{tabular}

$\beta$ was derived using linear regression analyses after controlling for age, gender, ethnicity, marital status, education and income, $* p<0.01$

conditions whilst work-loss and work-cutback days were based during the 30 days prior to the interview. Collection of the afore-mentioned data at the point of study entry would help us to further narrow down the conditions that affect work productivity and in turn help to curate better policies to tackle this issue. The study sample may also not be representative of Singapore's population in terms of statistics which shows that 'Associate Professionals and Technicians' are generally the biggest occupation group in Singapore in 2019 (SingStat 2020) while in the current study 'service and salesworker' were the largest group. All information in this study was obtained by self-report and this introduces potential the study.

\section{Conclusion}

This is one of the few representative studies which have provided a current comprehensive overview of mental and physical orders among the employed in Singapore. The study has shown that there are differences in the sociodemographic characteristics and prevalence of mental and physical disorders across occupational categories. These health disparities among occupations provide policymakers and researchers with vital information to pilot effective interventions that can improve the psychosocial and physical conditions at work. While occupations with higher odds of mental and physical disorders may be characterized by increased levels of job demands and lack of job security, decreased odds of these disorders among occupations are probably due to high levels of job discretion, good employee-employer relationship and clearly defined job scope (Stansfeld et al. 2011). Policies should be designed to lessen the impact of physical and mental disorders on employees which would contribute to a reduction in work-loss and work-cutback days. The findings also highlight the importance of investigating the causal relationship between the health conditions and work conditions, and identifying and reducing the risk factors experienced by employees. Targeted surveillance and health promotion programs can then be conducted for at-risk occupations.

Funding The study was funded by the Ministry of Health Singapore and Temasek Foundation Innovates.

Availability of data and material The data that support the findings of this study are available from the corresponding author upon reasonable request.

\section{Declarations}

Conflict of interest The authors have no conflict of interest to declare that are relevant to the content of this article.

Ethics approval The study was approved by the National Healthcare Groups' Domain Specific Review Board.

Research involving human and animal participants All procedures performed in studies involving human participants were in accordance with the ethical standards of the institutional and/or national research committee (National Healthcare Group Domain Specific Review Board 2015/01035) and with the 1964 Helsinki declaration and its later amendments or comparable ethical standards. This article does not contain any studies with animals performed by any of the authors. 


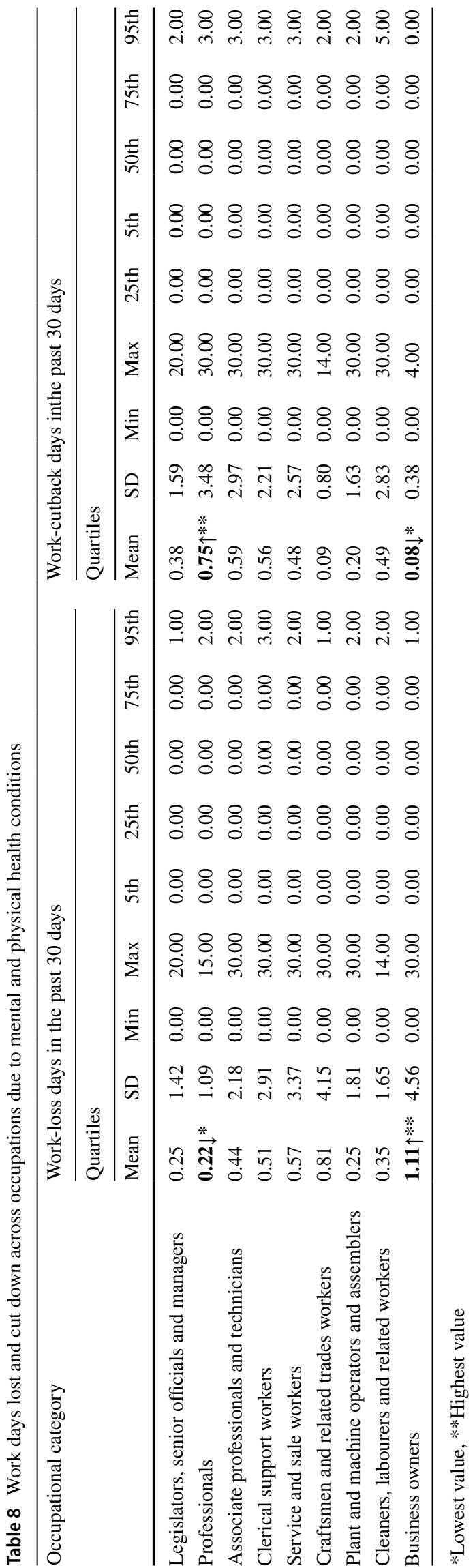

Informed consent Informed consent was obtained from all individual participants included in the study.

Open Access This article is licensed under a Creative Commons Attribution 4.0 International License, which permits use, sharing, adaptation, distribution and reproduction in any medium or format, as long as you give appropriate credit to the original author(s) and the source, provide a link to the Creative Commons licence, and indicate if changes were made. The images or other third party material in this article are included in the article's Creative Commons licence, unless indicated otherwise in a credit line to the material. If material is not included in the article's Creative Commons licence and your intended use is not permitted by statutory regulation or exceeds the permitted use, you will need to obtain permission directly from the copyright holder. To view a copy of this licence, visit http://creativecommons.org/licenses/by/4.0/.

\section{References}

American Psychiatric Association (1994) Diagnostic and statistical manual of mental disorders: DSM-IV. Washington,DC

Andrea H, Bültmann U, Beurskens AJHM et al (2004) Anxiety and depression in the working population using the HAD scale-psychometrics, prevalence and relationships with psychosocial work characteristics. Soc Psychiatry Psychiatr Epidemiol 39:637-646. https://doi.org/10.1007/s00127-004-0797-6

Bernard C, Courouve L, Bouée S et al (2011) Biomechanical and psychosocial work exposures and musculoskeletal symptoms among vineyard workers. J Occup Health 53:297-311. https://doi.org/10. 1539/joh.10-0031-OA

Boles M, Pelletier B, Lynch W (2004) The relationship between health risks and work productivity. J Occup Environ Med 46:737-745. https://doi.org/10.1097/01.jom.0000131830.45744.97

Cohidon C, Imbernon E, Gorldberg M (2009) Prevalence of common mental disorders and their work consequences in France, according to occupational category. Am J Ind Med 52:141-152. https:// doi.org/10.1002/ajim.20656

De Graaf R, Tuithof M, Van Dorsselaer S, Ten Have M (2012) Comparing the effects on work performance of mental and physical disorders. Soc Psychiatry Psychiatr Epidemiol 47:1873-1883. https://doi.org/10.1007/s00127-012-0496-7

Dodd KE, Mazurek JM (2016) Asthma among employed adults, by industry and occupation-21 states, 2013. Morb Mortal Wkly Rep 65:1325-1331. https://doi.org/10.15585/mmwr.mm6547a1

Gupta R, Deedwania PC, Sharma K et al (2012) Association of educational, occupational and socioeconomic status with cardiovascular risk factors in Asian Indians: a cross-sectional study. PLoS One. https://doi.org/10.1371/journal.pone.0044098

Herr RM, Bosch JA, Loerbroks A et al (2015) Three job stress models and their relationship with musculoskeletal pain in blue- and white-collar workers. J Psychosom Res 79:340-347. https://doi. org/10.1016/j.jpsychores.2015.08.001

Holden E (2011) Health and productivity: psychological distress is a major factor in productivity loss for a range of health conditions affecting Australian Workers Author School, Griffith University

International Labour Organization (2016) Employment Security.https:// www.ilo.org/global/lang--en/index.htm. Accessed 22 Feb 2021

Järvinen M, Ellergaard CH, Larsen AG (2014) Drinking successfully: Alcohol consumption, taste and social status. J Consum Cult 14:384-405. https://doi.org/10.1177/1469540513491856

Kang WY, Park WJ, Jang KH et al (2016) Comparison of anxiety and depression status between office and manufacturing job employees 
in a large manufacturing company: a cross sectional study. Ann Occup Environ Med. https://doi.org/10.1186/s40557-016-0134-Z

Karasek RA (1979) Job demands, job decision latitude, and mental strain: implications for job redesign. Adm Sci Q. https://doi.org/ $10.2307 / 2392498$

Kawakami N, Iwata N, Tanigawa T et al (1996) Prevalence of mood and anxiety disorders in a working population in Japan. J Occup Environ Med 38:899-905. https://doi.org/10.1097/00043764199609000-00012

Kessler RC, Ustün TB (2004) The World Mental Health (WMH) Survey Initiative Version of the World Health Organization (WHO) composite International Diagnostic Interview (CIDI). Int J Methods Psychiatr Res 13:93-121

Kessler RC, Akiskal HS, Ames M et al (2006) Prevalence and effects of mood disorders on work performance in a nationally representative sample of U.S. workers. Am J Psychiatry 163:1561-1568. https://doi.org/10.1176/ajp.2006.163.9.1561

Lee DJ, LeBlanc W, Fleming LE et al (2004) Trends in U.S. smoking rates in occupational groups: the National Health Interview Survey 1987-1994. J Occup Environ Med 46:538-548. https://doi. org/10.1097/01.jom.0000128152.01896.ae

Lim D, Sanderson K, Andrews G (2000) Lost productivity among fulltime workers with mental disorders. J Ment Heal Policy Econ 3:139-146. https://doi.org/10.1002/mhp.93

Lim W-Y, Fong CW, Chan JML et al (2007) Trends in alcohol consumption in Singapore 1992 2004. Alcohol Alcohol 42:354-361. https://doi.org/10.1093/alcalc/agm017

Linden M, Muschalla B (2007) Anxiety disorders and workplacerelated anxieties. J Anxiety Disord 21:467-474. https://doi.org/ 10.1016/j.janxdis.2006.06.006

Marchand A (2008) Alcohol use and misuse: What are the contributions of occupation and work organization conditions? BMCPublic Heal 2008 81 8:1-12. https://doi.org/10.1186/1471-2458-8-333

Ministry of Manpower Singapore (2020) Summary table: employment. https://stats.mom.gov.sg/Pages/Employment-Summary-Table. aspx. Accessed 21 Jun 2021

Ministry of Manpower (2019) Labour Market Report 2019. Singapore

Mitchell RJ, Bates P (2011) Measuring health-related productivity loss. Popul Health Manag 14:93-98. https://doi.org/10.1089/pop.2010. 0014

Nakamura S, Nakamura K, Tanaka M (2000) Increased risk of coronary heart disease in Japanese blue-collar workers. Occup Med(Chic Ill) 50:11-17. https://doi.org/10.1093/occmed/50.1.11

Netterstrom B, Conrad N, Bech P et al (2008) The relation between work-related psychosocial factors and the development of depression. Epidemiol Rev 30:118-132. https://doi.org/10.1093/epirev/ mxn004

Parker DA, Harford TC (1992) The epidemiology of alcohol consumption and dependence across occupations in the UnitedStates. Alcohol Health Res World 16:97-105

Pennanen M, Broms U, Korhonen T et al (2014) Smoking, nicotine dependence and nicotine intake by socio-economic status and marital status. Addict Behav 39:1145-1151. https://doi.org/10. 1016/j.addbeh.2014.03.005

Sanchez-Chaparro MA, Calvo-Bonacho E, Gonzalez-Quintela A et al (2008) Occupation-related differences in the prevalence of metabolic syndrome. Diabetes Care 31:1884-1885. https://doi.org/10. 2337/dc08-0431

Sanderson K, Andrews G (2006) Common mental disorders in the workforce: recent findings from descriptive and social epidemiology. Can J Psychiatry 51:63-75

Schäfer I (2012) Does multimorbidity influence the occurrence rates of chronic conditions? A claims data based comparison of expected and observed prevalence rates. PLoS ONE. https://doi.org/10. 1371/journal.pone. 0045390
Schyllert C, Andersson M, Lindberg A et al (2018) Childhood asthma affects job and education in young adults. Eur Respir J. https:// doi.org/10.1183/13993003.congress-2018.OA298

Shahwan S, Abdin E, Shafie S et al (2019) Prevalence and correlates of smoking and nicotine dependence: results of a nationwide cross-sectional survey among Singapore residents. BMJ Open 9:e032198. https://doi.org/10.1136/bmjopen-2019-032198

Siahpush M, McNeill A, Borland R, Fong GT (2006) Socioeconomic variations in nicotine dependence, self-efficacy, and intention to quit across four countries: findings from the International Tobacco Control (ITC) Four Country Survey. Tob Control 15:71-75. https://doi.org/10.1136/tc.2004.008763

SingStat (2019) Singapore Population Dashboard. https://www.sings tat.gov.sg/fid-data/search-by-theme/population/population-andpopulation-structure/visualising-data/population-dashboard. Accessed 22 Feb 2021

SingStat (2020) Singapore Department Of Statistics I SingStat Table Builder - Female Residents Aged 15 Years And Over ByLabour Force Status And Age Group, (June), Annual.https://www.table builder.singstat.gov.sg/publicfacing/createDataTable.action? refId $=12385$

Singapore Department of Statistics (2020) Singapore Standard Occupational Classification 2020. Singapore

Smith GD, Hart C, Blane D, et al (1997) Lifetime socioeconomic position and mortality: Prospective observational study. Br MedJ 314:547-552. https://doi.org/10.1136/bmj.314.7080.547

Stansfeld S, Candy B (2006) Psychosocial work environment and mental health - a meta-analytic review. Scand J Work Environ Heal 32:443-462. https://doi.org/10.5271/sjweh.1050

Stansfeld SA, Rasul FR, Head J, Singleton N (2011) Occupation and mental health in a national UK survey. Soc Psychiatry Psychiatr Epidemiol 46:101-110. https://doi.org/10.1007/ s00127-009-0173-7

Subramaniam M, Abdin E, Vaingankar JA et al (2019) Tracking the mental health of a nation: prevalence and correlates of mental disorders in the second Singapore mental health study. Epidemiol Psychiatr Sci. https://doi.org/10.1017/S2045796019000179

Tak JK (2002) Comparisons of job stressors and job stress among the white collar workers, the blue collar workers, and the professional research workers. Korean J Heal Psychol 7:125-141

Vaingankar J, Subramaniam M, Ann Chong S, et al (2015) Prevalence of chronic mental and physical disorders, impact on work productivity and correlates of alcohol use disorders and nicotine dependence across occupations. Ann Acad Med

Wakaizumi K, Yamada K, Oka H et al (2017) Fear-avoidance beliefs are independently associated with the prevalence of chronic pain in Japanese workers. J Anesth 31:255-262. https://doi.org/10. 1007/s00540-016-2303-1

Ware JE Jr, Mark K, Keller SD (1996) A 12-Item short-form health survey: construction of scales and preliminary tests of reliability and validity on JSTOR. Med Care 34:220-233

World Health Organization (1992) The ICD-10 classification of mental and behavioural disorders. Geneva

World Health Organization (2000) Mental health and work: Impact, issues and good practices. WHO, Geneva, pp 1-77

Zhang Z, Snizek WE (2003) Occupation, job characteristics, and the use of alcohol and other drugs. Soc Behav Pers 31:395-412. https://doi.org/10.2224/sbp.2003.31.4.395

Publisher's Note Springer Nature remains neutral with regard to jurisdictional claims in published maps and institutional affiliations. 